\title{
Treatment with Recombinant Human Tumor Necrosis Factor-Alpha Protects Rats Against the Lethality, Hypotension, and Hypothermia of Gram-Negative Sepsis
}

H. Richard Alexander, * Brett C. Sheppard, * J. Christian Jensen, * Howard N. Langstein, * Carolyn M. Buresh,* David Venzon," Elijah C. Walker," Douglas L. Fraker," Mark C. Stovroff," and Jeffrey A. Norton*

${ }^{*}$ Surgical Metabolism Section, Surgery Branch, and the ${ }^{\ddagger}$ Biostatistics and Data Management Branch of the Clinical Oncology Program of the National Cancer Institute; and the Biomedical Engineering and Instrumentation Branch of

the Division of Research Resources, National Institutes of Health, Bethesda, Maryland 20892

\begin{abstract}
Tumor necrosis factor (TNF) is a peptide secreted by macrophages in response to endotoxin that can produce many of the changes seen in septic shock. After cecal ligation and puncture (CLP) rats gradually develop tachycardia, hypotension, tachypnea, and hypothermia. At $5 \mathrm{~h}$ post-CLP, rats have a peak in serum levels of endotoxin and $60 \%$ of rats have blood cultures that grow Gram-negative rods (Escherichia coli and Klebsiella pneumonia). At $20 \mathrm{~h}$ post-CLP all rats develop positive blood cultures. Serum levels of TNF are not reproducibly measurable in rats following CLP. Rats undergoing CLP have a 50-80\% mortality with deaths usually occurring 24-72 h postinjury. Repetitive (twice daily $\times 6 \mathrm{~d}$ ) i.p. injection of sublethal doses of recombinant human $\mathrm{TNF}$-alpha $(100 \mu \mathrm{g} / \mathrm{kg})$ to rats undergoing CLP $1 \mathrm{~d}$ after the treatment period resulted in a significant reduction in mortality compared to control rats previously unexposed to rTNF $(P<0.03)$. Animals treated with rTNF had no hypotension or hypothermia after CLP and regained normal food intake faster than control rats. $12 \mathrm{~h}$ after CLP the gene expression for manganous superoxide dismutase (MnSOD), an inducible mitochondrial metalloenzyme responsible for cellular resistance to injury from toxic reactive oxygen species, was higher in livers of rats treated with rTNF suggesting that the TNF treatment augmented expression of this protective enzyme. Unlike MnSOD, expression of the gene for copper-zinc SOD was not affected by CLP or rTNF treatment. The results suggest that prior treatment with recombinant TNF can ameliorate the lethality, hypotension, hypothermia, and anorexia of Gram-negative sepsis in rats and that the mechanism may be related to enhanced hepatic expression of the gene for MnSOD. Repeated administration of recombinant TNF may be a strategy to minimize mortality and morbidity of Gramnegative sepsis. (J. Clin. Invest. 1991. 88:34-39.) Key words: cachectin $\cdot$ cytokine $\cdot$ tolerance
\end{abstract}

\section{Introduction}

A recent series of investigations has suggested that cachectin/ tumor necrosis factor (TNF) ${ }^{1}$ plays a prominent role in the

Address correspondence to Dr. Jeffrey A. Norton, Head, Surgical Metabolism Section, Surgery Branch, National Cancer Institute/National Institutes of Health, Building 10, Room 2B07, Bethesda, MD 20892.

Received for publication 15 March 1989 and in revised form 8 January 1991

1. Abbreviations used in this paper: CLP, cecal ligation and puncture; CuZnSOD, copper-zinc superoxide; MnSOD, manganous superoxide dismutase; ROS, reactive oxygen species; rTNF, recombinant TNF; TNF, tumor necrosis factor.

The Journal of Clinical Investigation, Inc.

Volume 88, July 1991, 34-39 toxic and lethal effects of septicemia and endotoxemia (1-6). Intravenous administration of recombinant human TNF results in the hemodynamic, hormonal, and metabolic changes of septic shock $(1,2)$. Intravenous administration of endotoxin to humans results in subsequent detection of circulating TNF levels (5), and antibodies to TNF protect mice against a lethal dose of endotoxin (3) and protect baboons against a lethal injection of Escherichia coli (4).

Our laboratory $(6,7)$ and others $(8-10)$ have noted tolerance to the anorectic effects of TNF with repetitive administration. In addition, we have noted that prior administration of recombinant (r) TNF-alpha also protects against a lethal injection of TNF or a lethal injection of endotoxin (6). TNF treatment has been shown to induce the gene expression for manganous superoxide dismutase (MnSOD) in vitro and in vivo (11-13). This enzyme is ubiquitously present in eukaryotic cells and is induced during conditions that generate toxic superoxide radicals $\left(\mathrm{O}_{2}^{-}\right)(14)$. $\mathrm{MnSOD}$ is responsible for the conversion of $\mathrm{O}_{2}^{-}$to the less reactive $\mathrm{H}_{2} \mathrm{O}_{2}$, and $\mathrm{O}_{2}$ and is thought to be a major protective mechanism against cellular injury from reactive oxygen species (ROS). This study demonstrates that prior treatment with recombinant human TNF-alpha protects rodents against the lethal, hypotensive, hypothermic, and anorectic effects of a clinically relevant model of Gram-negative sepsis, cecal ligation and puncture (CLP), and that this protection is associated with the enhanced liver gene expression of MnSOD.

\section{Methods}

\section{Cecal ligation and puncture}

This Gram-negative septic challenge was conducted as previously described (15). A 4-cm abdominal midline incision was made in rats previously anesthetized $(35 \mathrm{mg} / \mathrm{kg}$ pentobarbital i.p.), shaved, and prepped with Betadine. The cecum was identified and the avascular portion of the mesentery sharply incised. Stool was then milked from the proximal bowel into the cecum and a 3-0 silk ligature was placed just below the ileocecal valve. An 18-gauge angiocath (Abbott Laboratories, Inc., North Chicago, IL) was then used to make a single, antimesenteric puncture midway between the ligature and proximal cecum. The cecum was then returned to the abdominal cavity and the abdomen was approximated. Before closing the skin, normal saline $\left(5 \mathrm{~cm}^{3} /\right.$ $\mathrm{kg}$ ) was injected intraperitoneally. This septic model reliably resulted in a $50-80 \%$ mortality with deaths occurring $24-72 \mathrm{~h}$ postinjury. A few late deaths occurred $\sim 8-9 \mathrm{~d}$ after CLP. Surviving rats slowly returned to normal appearance and food intake.

\section{Model characterization}

Eight male F344 rats were anesthetized with intraperitoneal pentobarbital $(35 \mathrm{mg} / \mathrm{kg})$ and underwent catheterization of the right carotid artery. Polyethylene tubing (Clay Adams, Div. of Becton, Dickinson \& Co., Parsippany, NJ) was previously fashioned into an arterial line catheter by warming and melding PE-100 to PE-10 tubing. The arterial catheter was connected to a swivel apparatus that allowed unrestrained movement and continuous measurement of blood pressure and heart 
rate. Rats then underwent either cecal ligation and puncture $(n=5)$ or sham laparotomy $(n=3)$ and were placed in individual metabolic cages. Continuous back pressure was maintained on the arterial line by the use of a Medex pressure bag that flushed $2 \mathrm{ml}$ of heparin saline solution $(2 \mu / \mathrm{ml})$ every hour. Vital signs were recorded every $8 \mathrm{~h}$. Determinations of blood pressure and heart rate were made directly from the physiograph arterial line tracing. Respiratory rate was obtained by counting for $60 \mathrm{~s}$, and rectal temperature was measured by a digital rectal thermometer (Fisher Scientific Co., Pittsburgh, PA).

In a second experiment, 160 rats underwent CLP and were killed either immediately or at $1,2,3,4,5,6,7,8,10,11,12,14,15,20,24$, $25,30,36,40$, and $50 \mathrm{~h}$ after CLP to obtain blood for assay and culture. 20 rats were killed and exsanguinated at the initial time point (time 0 ). Blood was obtained under light pentobarbital anesthesia $(15 \mathrm{mg} / \mathrm{kg}$ i.p.) by aseptic infrarenal aortic cannulation and cultured for bacteria. Serum was separated and assayed for TNF activity by the L929 assay and endotoxin level by the limulus assay. For purpose of analysis rats were grouped at nearest time point and blood results were compared to rats that were killed immediately (time 0 ) after CLP as the control group.

L929 TNF bioassay. The TNF-sensitive L929 cells were plated on 96-well plates (Costar Corp., Cambridge, MA) and cultured overnight at $37.5^{\circ} \mathrm{C}$ in $5 \% \mathrm{CO}_{2}$ to establish a monolayer. On parallel plates, serial dilutions of serum samples were made in complete media with 1.5 $\mu \mathrm{g} / \mathrm{ml}$ actinomycin D (Merck, Sharp and Dohme, West Point, PA) and $100 \mu 1$ of this solution was transferred to plates with L929 cells giving a final concentration of $0.75 \mu \mathrm{g} / \mathrm{ml}$ of actinomycin D. After $18 \mathrm{~h}$ of further incubation, surviving cells were fixed, stained with $0.5 \%$ crystal violet (Sigma Chemical Co., St. Louis, MO), and the plates were counted in a titertek at $570 \mathrm{~nm}$. One unit of activity was defined as the reciprocal of the dilution required to produce a $50 \%$ decrease in absorbance relative to control cells exposed to actinomycin $D$ alone. The $50 \%$ decrease in absorbance was assessed by interpolation of absorbance measurements on a titertek. Each sample was assayed in triplicate and the third sample in each series was treated with a polyclonal neutralizing antibody to human TNF (Endogen, Inc., Boston, MA) to remove TNF activity. Samples were mixed in a 1:1 vol of $1: 100$ dilution of antibody and allowed to equilibrate for $90 \mathrm{~min}$ at $4^{\circ} \mathrm{C}$ before L929 assay. The lower limit of detection of TNF activity in serum was 4 $\mathrm{U} / \mathrm{ml}$. Each U/ml of TNF activity was the equivalent of $20 \mathrm{pg} / \mathrm{ml}$ of rhTNF (Cetus Corp., Emeryville, CA). Therefore, the detection limit of the $\mathrm{L} 929$ assay was $80 \mathrm{pg} / \mathrm{ml}$.

Limulus endotoxin assay. Determination of endotoxin levels was performed using a standard limulus test (Sigma Chemical Co.). Briefly, endotoxin-free glassware was prepared by autoclaving material at $121^{\circ} \mathrm{C}$ for $1 \mathrm{~h}$ followed by heating for $3 \mathrm{~h}$ at $175^{\circ} \mathrm{C}$ in an oven. Initial screening of serum samples suggested the presence of an inhibitor. Therefore all samples were heated at $75^{\circ} \mathrm{C}$ for 5 min and then diluted 1:10 in endotoxin-free water (16). Then $100 \mu l$ of previously obtained serum was coincubated with $100 \mu \mathrm{l}$ of limulus amebocyte lysate at $37.5^{\circ} \mathrm{C}$ for $1 \mathrm{~h}$ in a closed water bath. The presence of a hard gel, which did not disrupt on inversion, was taken as a positive test. Samples that tested positive were then serially diluted in endotoxin-free water and incubated as above. The endotoxin level was determined by multiplying the inverse of the highest dilution found positive by the lowest concentration of endotoxin standard found positive. The lower limits of endotoxin detection in serum was $40-60 \mathrm{pg} / \mathrm{ml}$.

Bacteriology. $1 \mathrm{ml}$ of whole blood was inoculated into $8 \mathrm{ml}$ enriched thioglycollate broth and $8 \mathrm{ml}$ of enriched brain-heart broth (BBL Microbiology Systems, Becton, Dickinson \& Co., Cockeysville, MD) and incubated for $72 \mathrm{~h}$ at $37.5^{\circ} \mathrm{C}$ in $5 \% \mathrm{CO}_{2}$. All samples were then Gram stained (Fisher Scientific). Gram-negative samples were then plated onto Mac-Conkey's agar (Difco Laboratories Inc., Detroit, MI) and incubated under aerobic conditions, or plated onto special anaerobe blood plates (BBL) and incubated under anaerobic conditions (Gaspak Plus; BBL) for $48 \mathrm{~h}$. Single colonies were then inoculated into a self-contained battery of biochemical tests (Enterotube II; Roche Diagnostics, Nutley, NJ).

\section{TNF treatment and its effect on CLP}

20 male F344 rats weighing between 200 and $280 \mathrm{~g}$ were placed in individually housed cages and allowed free access to water. A nonscatterable casein-based paste diet (C-21; ICN Nutritional Biochemicals, Cleveland, $\mathrm{OH}$ ) was used to enable accurate measurement of food intake (17). Before study, rats were allowed to accommodate to their environment for $5 \mathrm{~d}$. Body weight and food intake were measured daily. When food intake and body weight gain stabilized, rats were randomized in equal groups to receive either $100 \mu \mathrm{g} / \mathrm{kg}$ of rTNF (Cetus Corp.) i.p. twice daily (BID) for $6 \mathrm{~d}$ or control vehicle (PBS with $0.5 \%$ BSA). Human rTNF had a sp act of between 1 and $2.5 \times 10^{7} \mathrm{U} / \mathrm{mg}$ as measured by the $L 929$ bioassay and an endotoxin level of between 30 and $50 \mathrm{pg} / 6.5 \times 10^{6} \mathrm{U}$ as measured by the limulus assay $(6,18)$. These measurements were provided by Cetus and were confirmed in our assays.

In two additional experiments, similarly treated rats then underwent CLP to determine the effects of TNF treatment on the lethality and nutritional morbidity of CLP. In these experiments, CLP was performed $24 \mathrm{~h}$ after the last dose of TNF. After CLP, survival, food intake, and body weight were measured daily for $20 \mathrm{~d}$. When an individual rat regained normal food intake (defined as the average amount consumed during the $3 \mathrm{~d}$ before the administration of TNF) or suffered death, it completed the observation period. This survival experiment was initially performed using 19 rats, 9 randomized to TNF and 10 control. It was then repeated using 25 rats, 10 TNF and 15 control.

Other experiments were performed to determine whether measured physiological and blood parameters were different in control survivors, control nonsurvivors, rTNF-treated survivors, and rTNF-treated nonsurvivors after CLP. rTNF-treated rats $(100 \mu \mathrm{g} / \mathrm{kg}$ i.p. BID $\times 6 \mathrm{~d}, n=5)$ and saline-treated rats (control, $n=11$ ) underwent CLP after placement of a carotid artery catheter $1 \mathrm{~d}$ after the 6-d treatment period. Each rat was housed in an individual metabolic cage as previously described. Vital signs were obtained every $6 \mathrm{~h}$ for between 24 and $36 \mathrm{~h}$. $0.5-\mathrm{ml}$ blood samples were collected through the arterial catheter at time $0,6,12$, and $18 \mathrm{~h}$ for culture, and for serum levels of LPS, TNF activity by the L929 assay, and TNF by a commercially available ELISA for the measurement of murine TNF (Genzyme Corp., Cambridge, MA). Saline was reinfused to correct for phlebotomy volumes. Rats were allowed free access to food and water after the initial $24 \mathrm{~h}$ and survival was assessed daily for $1 \mathrm{wk}$. Two additional rats were given LPS (Sigma) $15 \mathrm{mg} / \mathrm{kg}$ i.p. and serum was collected before and $90 \mathrm{~min}$ after LPS and assayed for level of LPS, TNF activity, and TNF level to serve as a positive control. Additional experiments were performed in similarly treated rats to again measure TNF levels by the two assays after CLP.

\section{Northern blot hybridization}

18 rats were treated with rTNF or saline and underwent CLP as described. Livers from rats were harvested under pentobarbital anesthesia at time 0 (no CLP), 12, and $24 \mathrm{~h}$, and frozen in liquid nitrogen. Livers were harvested at each time point $(n=3)$, crushed with a mortar and pestle precooled in liquid nitrogen, homogenized at $4^{\circ} \mathrm{C}$ in guanidium isothiocyanate, and RNA separated over a cesium chloride gradient. Methods used for RNA extraction, preparation, electrophoresis, and hybridization have been previously described (19). RNA was hybridized with human cDNA probes for MnSOD (a generous gift from $G$. $H$. Wong, Genentech, San Francisco, CA) (11), copper-zinc SOD (CuZnSOD; a generous gift from A. Singh, Genentech, San Francisco, CA) (11), and beta-actin (19). Gel densitometry (Beckman Instruments, Carlsbad, CA) was performed to quantitate image density.

\section{Statistics}

Data are presented as mean \pm SEM unless otherwise stated. Survival curves were analyzed for significant differences by the Breslow modifcation of the Kruskal-Wallis test (20). Parametric data were compared by the two-sample $t$ test, and nonparametric data were compared by Wilcoxon rank sum test corrected for multiple comparisons. Propor- 
tions were compared by the Fisher's exact test. In the final experiment data were analyzed using the test for linear trend in a repeated measures analysis of variance.

\section{Results}

Characterization of cecal ligation and puncture. There were significant increases in heart rate of rats undergoing CLP compared to sham-operated control rats at 16 and $24 \mathrm{~h}$ postinjury (Fig. 1). Heart rate of CLP rats then returned to levels similar to sham-operated control animals until another significant late tachycardia occurred at $56 \mathrm{~h}$ postinjury. Levels of mean arterial pressure were significantly decreased in rats undergoing CLP compared to sham-operated controls from $24 \mathrm{~h}$ postinjury until death (Fig. 1). Respiratory rate of rats undergoing CLP was significantly increased at 24,56 , and $72 \mathrm{~h}$ after injury compared to sham-operated controls (Fig. 1). Rats in both groups were initially hypothermic and became euthermic by $8 \mathrm{~h}$ postoperatively. CLP animals demonstrated significant hypothermia at $24 \mathrm{~h}$ postinjury compared to euthermia in sham-operated control rats. Significant hypothermia persisted until death of CLP rats (Fig. 1).

When 20 rats were bled immediately after CLP (time 0 ), no animal had detectable serum levels of TNF activity, endotoxin, or blood levels of bacteria (Fig. 2). These animals served as the control group for the analysis of serum levels of LPS and TNF activity and blood culture results after CLP. Serum levels of endotoxin reached an early significant peak of $1.4 \pm 0.6 \mathrm{ng} / \mathrm{ml}$ at $5 \mathrm{~h}$ post-CLP compared to undetectable levels at the time of CLP and returned to near baseline levels until a second similar significant peak at $40 \mathrm{~h}$. Serum levels of TNF activity (L929

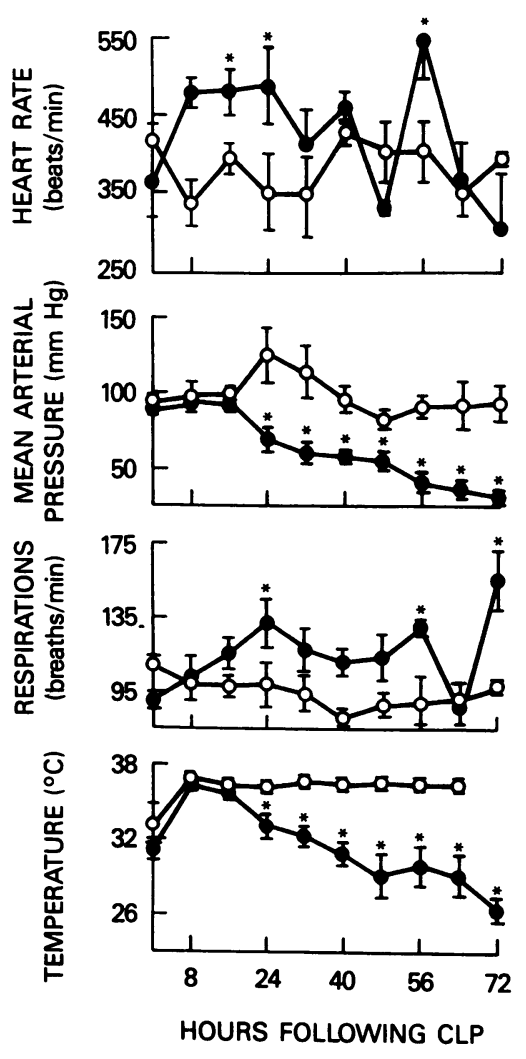

Figure 1. Physiological measurements following cecal ligation and puncture or sham operation. Five rats underwent CLP (closed circles) (see Methods) and three rats (open circles) underwent sham laparotomy and had carotid artery catheters placed at time 0 . Physiological measurements were obtained every $8 \mathrm{~h}$. The combination of CLP and carotid artery catheterization resulted in the death of some of the CLP rats at $\sim 72 \mathrm{~h}$. Each of the five CLP rats survived at least 70 h. None of the shamoperated rats died. Differences between CLP and sham-operated rats were assessed by the Wilcoxon rank sum test. Asterisks indicate that there is a significant difference at the $P<0.05$ level between the two groups.

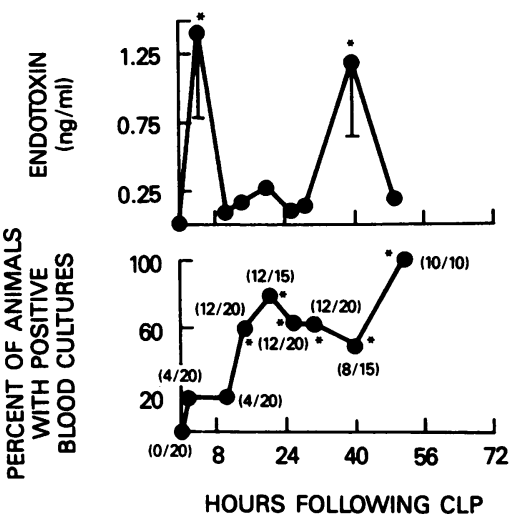

Figure 2. Blood parameters following cecal ligation and puncture. Serum endotoxin and blood culture results of rats $(n=160)$ killed immediately after $(n=20$, time 0 ) and at various subsequent times after CLP. Data are mean \pm SEM for serum levels of endotoxin and are compared to levels at time 0 by independent Student's $t$ test.

Asterisks indicate significant difference from time 0 level $(P<0.05)$. Percentages for rats with positive blood cultures are given. In parentheses, numerator indicates the number of animals with positive blood cultures and denominator indicates the total number of animals studied at each time point. Asterisks indicate that there is a significant difference in proportions compared to animals at time 0 by Fisher's exact test $(P<0.01)$

assay) or immunologic reactivity (ELISA) were not reproducibly measurable in rats following CLP.

Blood cultures did not grow any Gram-positive bacteria or bacteroides species. The predominant bacteria isolated was $E$. coli (75\% of isolates) and the remainder was Klebsiella pneumo nia. $20 \%(4 / 20)$ of blood cultures grew bacteria at 2 and $10 \mathrm{~h}$ after CLP which was not different from control. However, at 15 $h$ post-CLP $60 \%$ (12/20) of blood cultures became positive and this observation was different from the negative cultures at time 0. It was at $24 \mathrm{~h}$ after CLP that the mean arterial pressure and the temperature began its progressive decline (Fig. 1) and that a significant proportion of blood cultures became positive (Fig. 2).

TNF treatment and its effect on CLP. Rats given human rTNF i.p. twice daily for $6 \mathrm{~d}$ decreased food intake and ate significantly less food than control rats given saline. However, despite repetitive daily administration of rTNF, rats progressively increased daily food intake over levels consumed on the previous day. On day 6 of rTNF treatment, rats consumed the same amount of food as saline-treated controls (data not shown, but similar to references 6 and 7). Similarly, rats given rTNF lost body weight only on the initial day of administration, while saline control rats did not; but by day 2 , rats administered rTNF began to gain body weight and on treatment days 3-6 gained similar amounts of body weight as controls (data not shown but similar to references 6 and 7).

In two separate experiments, rats treated with rTNF that subsequently underwent CLP had significantly improved survival compared to rats previously treated with saline (Fig. 3). In addition, rats from the control group that survived CLP took twice as long to return to normal food intake as rats previously treated with rTNF. Median days to normal food intake after CLP were $8 \mathrm{~d}$ for rTNF-treated rats and $15 \mathrm{~d}$ for control rats; the difference in time was significant $(P<0.03)$ and repeatable in the second experiment (data not shown).

Rats that were treated with rTNF and subsequently underwent carotid artery catheter placement and CLP had significantly improved survival compared to controls $(P<0.01)$ (Fig. $4 a$ ). Only two of eleven control rats survived while five of five TNF-treated rats survived. Eight of nine deaths in the control 

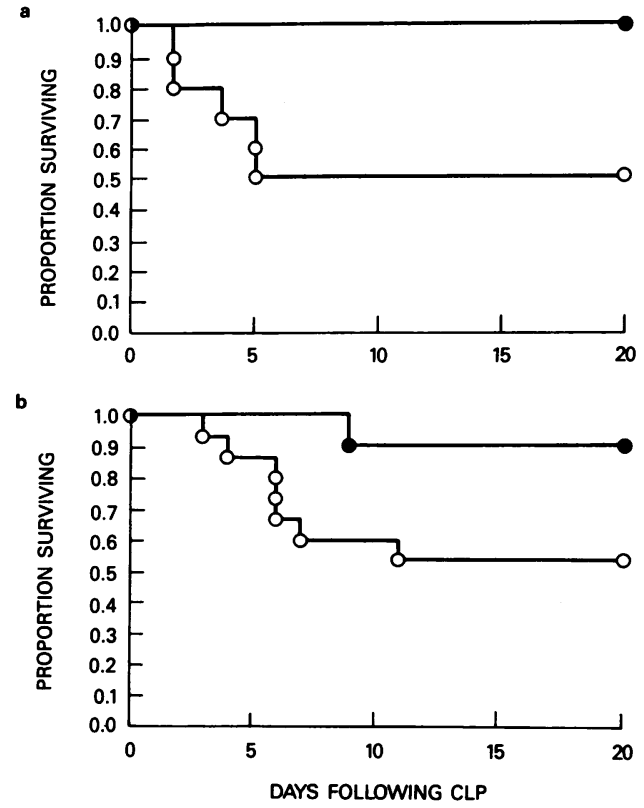

Figure 3. Mortality of cecal ligation and puncture in control and rTNF-treated rats. (a) Rats were treated with $\mathrm{rTNF}(100 \mu \mathrm{g} / \mathrm{kg}$ i.p. BID $\times 6 \mathrm{~d})(n=9$, closed circles $)$ or saline vehicle $(n=10$, open circles). $24 \mathrm{~h}$ later CLP was performed (day 0) and 20-d survival was assessed. Rats treated with rTNF had significantly improved survival $(P$ $<0.03$ ). (b) Repeat experiment with identical conditions except that there were 10 rats in the rTNF group (closed circles) and 15 rats in the control group (open circles). Rats treated with rhTNF again had significantly improved survival $(P<0.02)$.

group occurred by $48 \mathrm{~h}$. There were no differences in pulse or respirations between the two groups. Immediately after CLP, control rats had significantly higher mean arterial pressure that progressively decreased during the 30 -h measurement period $(P<0.02$, Fig. $4 b)$. Rats previously treated with rTNF had no significant change in mean arterial pressure during the $30-\mathrm{h}$ period. Temperature was significantly decreased in control rats that did not survive CLP compared to rats previously treated with rTNF and control rats that did survive CLP. This difference was first significant at $18 \mathrm{~h}$ after $\operatorname{CLP}(P<0.001)$ (Fig. $4 c)$.

Rats from control and rTNF treatment groups each had immediate positive blood cultures drawn through the carotid artery line $(\sim 45 \mathrm{~min}$ after CLP) and cultures remained positive at each time point. Serum endotoxin levels peaked at $12 \mathrm{~h}$ after CLP in these rats $(675 \pm 125 \mathrm{pg} / \mathrm{ml})$ and levels at $24 \mathrm{~h}$ remained similar but slightly reduced. There were no significant differences in serum endotoxin levels in control or rTNFtreated rats. Levels of serum TNF activity were below the limit of detection of the assay in all rats. Control rats treated with intraperitoneal endotoxin had serum endotoxin levels equal to $27 \pm 14 \mathrm{ng} / \mathrm{ml}$ and serum TNF activity levels equal to $640 \pm 0$ $\mathrm{U} / \mathrm{ml}$ at $90 \mathrm{~min}$ after endotoxin. Levels of each were undetectable before endotoxin.

Before CLP $(t=0)$ the gene for MnSOD was only minimally detectable in the liver of control animals but was slightly amplified in the liver of rTNF-treated rats (Fig. 5). Expression of the gene for CuZnSOD was equal in the liver of control and rTNF-treated rats and did not change after CLP. However, in both rTNF- and saline-treated animals, the gene for MnSOD was augmented at $12 \mathrm{~h}$ after CLP compared to $\mathrm{t}=0$ levels. In
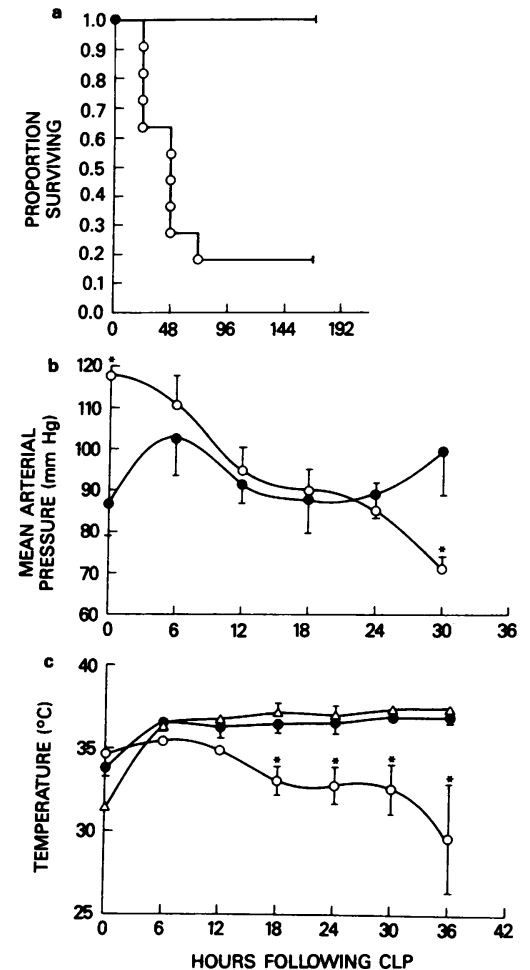

Figure 4. Mortality and physiological parameters of control and rTNF-treated rats after carotid arterial catheter placement and CLP. (a) Rats were treated with rTNF $(100 \mu \mathrm{g} / \mathrm{kg}$ i.p. BID $\times 6 \mathrm{~d})(n=5$, closed circles) or saline vehicle ( $n=11$, open circles) and $1 \mathrm{~d}$ later underwent carotid artery catheter placement and CLP. Physiological parameters and blood were obtained every $6 \mathrm{~h}$ for $30 \mathrm{~h}$ and survival was assessed daily for 7 d. Rats treated with rTNF had significantly improved survival $(P$ $<0.01$ ). (b) Mean arterial pressure measurements of rats described in $(a)$. Mean arterial pressure was significantly increased in control rats (open circles) compared to rTNFtreated rats (closed circles) immediately after $\operatorname{CLP}\left({ }^{*} P<0.02\right)$. Analysis of variance demonstrated that mean arterial pressure did not change in TNF-treated rats, but significantly progressively decreased in control rats over $30 \mathrm{~h}(P=0.02)$. (c) Temperature of rats described in $(a)$. Temperature was significantly decreased in control rats that did not survive (open circles) compared to TNF-treated rats (closed circles) and control rats that survived (open triangles). Analysis of variance demonstrated that these findings were significant at $18 \mathrm{~h}$ post-CLP and remained significant throughout $\left({ }^{*} P<0.01\right)$.

addition, $12 \mathrm{~h}$ after CLP hepatic gene expression of MnSOD was increased much more markedly in the livers of rats treated with rTNF. $1 \mathrm{~d}$ after CLP liver MnSOD gene expression returned to levels similar to baseline levels except that the expression in control animals appeared slightly greater than rTNFtreated rats (Fig. 5).

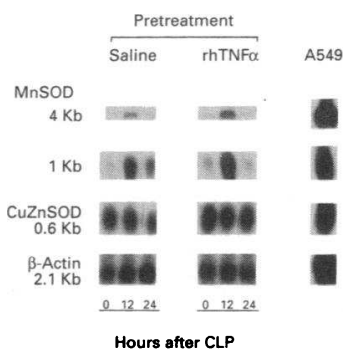

Figure 5. Gene expression of MnSOD after CLP in the liver of rTNF- or saline-treated rats. Animals were treated with rTNF or saline control as described and underwent CLP $24 \mathrm{~h}$ later. RNA was extracted from liver at each time point. At $t=0$, before CLP, there is evidence of slightly increased expression of the gene for MnSOD in the liver of rats treated with rTNF compared to controls. $12 \mathrm{~h}$ after CLP

there is clear augmentation of the gene for MnSOD observed in both the control and rTNF-treated rats compared to levels at $\mathbf{t}=\mathbf{0}$. In addition, at $12 \mathrm{~h}$ MnSOD gene expression is further augmented in the liver of rTNF treated compared to control rats. After $24 \mathrm{~h}$ MnSOD gene expression returns to basal levels in both groups. The hepatic gene expression for $\mathrm{CuZnSOD}$ and beta-actin remains the same before and at each time point after CLP in either rTNF or saline control animals. RNA extracted from A549 cells treated with $0.1 \mu \mathrm{g}$ LPS (Sigma) served as a positive control. 


\section{Discussion}

Previous studies in our laboratory have demonstrated that resistance to the anorectic and weight loss effects of recombinant human TNF/cachectin develops during a repeated twice daily dosage schedule. Additionally, similar rTNF treatment regimens confer protection when rats or mice were subsequently challenged with a lethal dose of endotoxin or TNF $(6,21)$. In vitro and in vivo TNF has been shown to induce MnSOD, a metalloenzyme that reduces ROS to less toxic $\mathrm{H}_{2} \mathrm{O}_{2}$ and $\mathrm{O}_{2}$ (11). This enzyme is induced in a variety of tissues, including rat liver, during conditions that generate a free radical stress and is thought to be responsible for cellular resistance to injury from $\operatorname{ROS}(14,22)$.

In this work we have examined the possibility that prior treatment with recombinant human TNF may offer protection from death and minimize the toxicity of a septic challenge. While this Gram-negative sepsis model is not as well quantified as a bacterial innoculum, cecal ligation and puncture is advantageous as it develops slowly and simulates a polymicrobial enteric insult that is similar to that seen in patients with colonic perforations. When compared to sham-operated controls, rats undergoing CLP develop tachycardia at $16 \mathrm{~h}$ postinjury, followed by hypotension, hypothermia, and tachypnea at $24 \mathrm{~h}$ postinjury (Fig. 1). In rats bled and killed after CLP, peak levels of endotoxin in serum occurred $5 \mathrm{~h}$ after injury and then levels rapidly decreased.

Serum levels of TNF activity were not reproducibly measurable in animals despite the endotoxin peak. At $20 \mathrm{~h}$ after CLP there was a significant rise in the number of rats with positive blood cultures $(60 \%)$ and the proportion later further increased to $100 \%$ at $50 \mathrm{~h}$ postinjury (Fig. 2). Circulating levels of TNF have been detected by others in a limited number of heterogeneous studies of infection. Serum levels of TNF have been elevated in patients with fatal infectious diseases, including AIDS (23), meningococcemia $(24,25)$, and fulminant hepatic failure secondary to sepsis (26). Similarly, serum levels of TNF have been detectable in experimental sepsis with Listeria (27) and $E$. coli (28). However, in other experimental models of infection, such as infected burns (29), Listeria meningitis (30), or Salmonellosis (31), serum levels of TNF have been slightly elevated in occasional animals $(28)$ or not detectable $(29,30)$. The fact that TNF was not reproducibly measurable may imply that there is an episodic and not continuous secretion of TNF after CLP. Because one is limited by the amount and number of blood samples that can be drawn in a small animal like the rat, it is possible to miss an episodic peak in serum TNF activity. Another recent study in mice also did not detect circulating levels of TNF after CLP (32). As others have described in an infected burn model (29), in rats that have undergone CLP we have recently observed an induction of TNF gene expression in a variety of tissues, including lung, liver, and spleen, suggesting that production of this cytokine is augmented (Alexander, H. R., unpublished observations).

The recent observation that tolerance or resistance to the toxic and lethal effects of recombinant tumor necrosis factor/ cachectin can occur has been made concomitantly by several groups working with recombinant TNF $(6-9,16,33)$. The observation that treatment with rTNF can protect against the morbidity and mortality of Gram-negative sepsis described here may have clinical relevance. Previous treatment with TNF not only reduces the lethality (Figs. 3 and $4 a$ ) of these infec- tions, but it significantly improves the marked hypothermia and hypotension of the sepsis (Fig. 4, $b$ and $c$ ). Temperature changes (fever in higher mammals) is one of the most prevalent clinical features of infection. Prior treatment with TNF appears to abrogate the equivalent to fever and shock in septic rats. Blood pressure and temperature is maintained in the normal range, while control rats become hypotensive and hypothermic. In addition, the time to recovery of normal food intake is significantly shorter in TNF-treated rats than control survivors. Previous work in our laboratory demonstrated that similar TNF treatment also minimized the marked cellular damage associated with high doses of endotoxin and that this protection lasted between 4 and $14 \mathrm{~d}$ after the discontinuation of treatment (6). In addition, the protection does not appear to be induced by endotoxin contamination of the recombinant hTNF preparations because the rTNF is very low in endotoxin, and macrophages from TNF-treated animals respond differently than macrophages from LPS-treated animals, implying that the mechanisms are different (16). Finally, recent work suggests that similar protection to the lethal effects of TNF, endotoxin, and CLP can also be induced by a single intravenous injection of rTNF, further supporting possible clinical applications (34).

In vitro, TNF induction of MnSOD has been implicated as the protective mechanism against cellular injury from free radical stress (13). In the liver of rTNF-treated rats (compared to control animals) there is a slight enhancement of the low level of expression of the gene for MnSOD $24 \mathrm{~h}$ after the treatment period just before $\operatorname{CLP}(t=0)($ Fig. 5). This indicates that in the multiple dose experiments described here, rTNF treatment, unlike the single intravenous dose model previously reported (11), did not markedly induce MnSOD, but there was still some evidence of TNF induction of the gene for hepatic MnSOD suggesting that it may be part of the protective mechanism. $12 \mathrm{~h}$ after CLP there is a clear increase in hepatic MnSOD gene expression in control animals implying a significant free radical stress as a result of CLP. In the liver of animals treated with rTNF, there is a marked additional augmentation of the gene for this protective enzyme. Our experiments do not attempt to dissect the regulation of hepatic MnSOD gene expression but it appears clear that at $12 \mathrm{~h}$ after CLP transcription of this gene is increased by prior treatment with rTNF. Interestingly, this is just before the time ( $18 \mathrm{~h}$ post-CLP) when physiological differences between the TNF and control group are first observed (Fig. 4). In contrast, as previously described $\mathrm{CuZn-}$ SOD is a noninducible cytosolic enzyme that is constitutively expressed in tissue (14), and the results demonstrated here also clearly indicate that CuZnSOD is not responsible for any TNFinduced differences. In these studies neither TNF treatment nor the subsequent CLP changed the gene expression of CuZnSOD.

The fact that MnSOD expression is very low at $24 \mathrm{~h}$ after CLP (in fact, TNF-treated are less than control) suggests that the gene expression seen at $12 \mathrm{~h}$ has generated enough enzyme activity to withstand the oxidant stress of CLP. Experiments in a murine model of endotoxin shock are currently being performed in our laboratory to evaluate this possibility. The marked improvement in survival seen with rTNF treatment and its dramatic improvement in hypotension and hypothermia after CLP may suggest that induction of the gene for MnSOD in the liver is not the only mechanism of TNF-induced protection. Furthermore, TNF increases neutrophil ac- 
tivity $(35,36)$ which may also be a protective action of the cytokine. Finally, recent work suggests that there exists a soluble fragment of the TNF receptor molecule that may serve as a TNF inhibitor (37). Part of the explanation of the mechanism of the dramatic protective effects of TNF treatment described here may be the induction of a soluble TNF receptor fragment that reduces circulating levels of TNF activity. Our inability to measure circulating levels of TNF activity may be consistent with this hypothesis. However, there did not appear to be a difference in ability to measure levels of serum TNF activity after CLP in control or rTNF-treated rats.

In summary, rats treated with recombinant human TNFalpha develop resistance to the anorectic and weight loss effects of TNF and protection against the lethal, hypotensive, hypothermic, and anorectic effects of an experimental model of sepsis, cecal ligation and puncture. The protective mechanism may be mediated by a TNF-induced augmentation of expression of the gene for MnSOD, an enzyme that is maximally expressed at $12 \mathrm{~h}$ after CLP. This work documents that treatment with rTNF may have use in minimizing the morbidity and mortality of Gram-negative sepsis.

\section{References}

1. Tracey, K. J., B. Beutler, S. F. Lowry, J. Merryweather, S. Wolpe, I. W Milsark, R. J. Hariri, T. J. Fahey, A. Zentella, J. D. Alpert, et al. 1986. Shock and tissue injury induced by recombinant human cachectin. Science (Wash. DC) 234:470-474.

2. Tracey, K. J., S. F. Lowry, T. J. Fahey, J. D. Albert, Y. Fong, D. Hesse, B. Brutler, K. R. Manogue, S. Calvano, H. Wei, et al. 1987. Cachectin/tumor necrosis factor induces lethal shock and stress hormone responses in the dog. Surg. Gynec. \& Obstet. 106:415-422.

3. Beutler, B., I. W. Milsark, and A. C. Genami. 1985. Passive immunization against cachectin/tumor necrosis factor protects mice from lethal effect of endotoxin. Science (Wash. DC). 228:869-871.

4. Tracey, K. J., Y. Fong, D. G. Hesse, K. R. Manogue, A. T. Lee, G. C. Kuo, S. F. Lowry, and A. Cerami. 1987. Anti-cachectin/TNF monoclonal antibodies prevent septic shock during lethal bacteremia. Nature (Lond.). 330:662-664.

5. Michie, H. R., K. R. Manogue, D. R. Spriggs, A. Revhaug, S. O'Dwyer, C. Dinarello, C. A. Cerami, S. M. Wolff, and D. W. Wilmore. 1988. Detection of circulating tumor necrosis factor after endotoxin administration. N. Engl. J. Med. 318:1481-1486.

6. Fraker, D. L., M. C. Stovroff, M. J. Merino, and J. A. Norton. 1988. Tolerance to tumor necrosis factor in rats and the relationship to endotoxin tolerance and toxicity. J. Exp. Med. 168:95-105.

7. Stovroff, M. D., D. L. Fraker, J. A. Swedenborg, and J. A. Norton. 1988. Cachectin/tumor necrosis factor: a possible mediator of cancer anorexia in the rat. Cancer Res. 48:4567-4572.

8. Patton, J. S., P. M. Peters, J. McCabe, D. Crase, S. Hansen, A. B. Chen, and D. Liggitt. 1987. Development of partial tolerance to the gastrointestinal effects of high doses of recombinant tumor necrosis factor- $\alpha$ in rodents. J. Clin. Invest. 80:1587-1596.

9. Socher, S. H., A. Friedman, and D. Martinez. 1988. Recombinant human tumor necrosis factor induces acute reductions in food intake and body weight in mice. J. Exp. Med. 167:1957-1962.

10. Cerami, A., and B. Beutler. 1988. The role of cachectin/TNF in endotoxic shock and cachexia. Immunol. Today. 9:28-31.

11. Wong, G. H., and D. V. Goeddel. 1988. Induction of manganous superoxide dismutase by tumor necrosis factor: possible protective mechanism. Science (Wash. DC). 242:941-944.

12. Asoh, K., Y. Watanabe, H. Mizoguchi, M. Mawatari, M. Ono, K. Kohno, and $K$. and $M$. Kuwano. 1989. Induction of manganous superoxide dismutase by tumor necrosis factor in human breast cancer MCF-7 cell line and its TNF-resistant variant. Biochem. Biophys. Res. Commun. 162:794-801.

13. Wong, G. H. W., J. H. Elwell, L. H. Oberley, and D. V. Goeddel. 1989.
Manganous superoxide dismutase is essential for cellular resistance to cytotoxicity of tumor necrosis factor. Cell. 58:923-931.

14. Bannister, J. V., W. H. Bannister, and G. Rotilio. 1987. Aspects of the structure, function, and applications of superoxide dismutase. Crit. Rev. Bio chem. 22:111-180.

15. Wichterman, K. A., A. E. Baue, and I. H. Chaudry. 1980. Sepsis and septic shock: a review of laboratory models and a proposal. $J$. Surg. Res. 29:189-201.

16. Harris, R. I., R. W. Stone, and J. Steart. 1983. An improved chromogenic substrate endotoxin assay for clinical use. J. Clin. Pathol. (Lond.). 36:1145-1149.

17. Peacock, J. L., C. M. Gorschboth, and J. A. Norton. 1987. Impact of insulin on doxorubicin-induced rat host toxicity and tumor regression. Cancer Res. 47:4318-4322.

18. Asher, A., J. J. Mule, C. M. Reichert, E. Shiloni, and S. A. Rosenberg. 1987. Studies on the anti-tumor efficacy of systemically administered recombinant tumor necrosis factor against several murine tumors in vivo. J. Immunol. 138:963-974.

19. Kasid, A., E. O. Director, and S. A. Rosenberg. 1989. Induction of endogenous cytokine-mRNA in circulating peripheral blood mononuclear cells by IL-2 administration in cancer patients. J. Immunol. 143:736-741.

20. Breslow, N. 1970. A generalized Kruskal-Wallis test for comparing K samples subject to unequal patterns of censorship. Biometrika. 57:579-594.

21. Fraker, D. L., and J. A. Norton. 1988. TNF and endotoxin: cross-tolerance by different mechanisms. Surg. Forum. 34:15-17.

22. Dryer, S. E., R. L. Dryer, and A. P. Antor. 1980. Enhancement of mitochondrial, cyanide-resistant superoxide dismutase in the livers of rats treated with 2,4-dinitrophenol. J. Biol. Chem. 255:1054-1057.

23. Lahdevirta, J., C. P. J. Maury, A. M. Teppo, and H. Repo. 1988. Elevated levels of circulating cachectin/tumor necrosis factor in patients with acquired immunodeficiency syndrome. Am. J. Med. 85:289-291.

24. Girardin, E., G. E. Grau, J. M. Dayer, P. Roux-Lombard, and P. H. Lambent. 1988. Tumor necrosis factor and interleukin-1 in the serum of children with severe infectious purpura. N. Engl. J. Med. 319:397-400.

25. Waage, A., T. Espevik, and A. Habtensen. 1987. Association between tumor necrosis factor in serum and fatal outcome in patients with meningococcal disease. Lancet. i:355-357.

26. Muto, Y., A. Meager, A. L. W. F. Eddleston, K. T. Nouri-Area, G. J. M. Alexander, and R. Williams. 1988. Enhanced tumor necrosis factor and interleukin-1 in fulminant hepatic failure. Lancet. ii:72-74.

27. Havell, E. A. 1987. Production of tumor necrosis factor during murine listerosis. J. Immunol. 139:4225-4231.

28. Hesse, D. G., K. J. Tracey, Y. Fong, K. R. Manogue, M. A. Palladino, A. Cerami, G. T. Shires, and S. F. Lowry. 1988. Cytokine appearance in human endotoxemia and primate bacteremia. Surg. Gynec. \& Obstet. 166:148-153.

29. Marano, M. A., L. L. Moldawer, Y. Fong, H. Wei, J. Minei, R. Yurt, A Cerami, and S. F. Lowry. 1988. Cachectin/TNF production in experimenta burns and Pseudomonas infection. Arch. Surg. 123:1383-1388.

30. Leist, T. P., K. Frei, S. Kam-Hansen, R. M. Zinkernagel, and A. Fontana 1988. Tumor necrosis factor $\alpha$ in cerebrospinal fluid during bacterial, but not viral, meningitis. Evaluation in murine model infections and in patients. $J$. Exp. Med. 167:1743-1748.

31. Peel, J. E., M.-J. Voirol, C. Kolly, D. Gobet, and S. Martinod. 1990. Induction of circulating tumor necrosis factor cannot be demonstrated during septicemic Salmonellosis in calves. Infect. Immun. 58:439-442.

32. Evans, G. F., Y. M. Snyder, L. D. Butler, and S. H. Zuckerman. 1989. Differential expression of interleukin-1 and tumor necrosis factor in murine septic shock models. Circ. Shock. 29:279-290.

33. Wallach, D., H. Holtmann, H. Engelmann, and Y. Nophar. 1988. Sensitization and desensitization to the lethal effects of tumor necrosis factor and IL-1. J. Immunol. 140:2994-2999.

34. Sheppard, B. C., D. L. Fraker, and J. A. Norton. 1989. Prevention and treatment of endotoxin and sepsis lethality with recombinant human tumor necrosis factor. Surgery (St. Louis). 106:156-162.

35. Berkow, R. L., D. Wang, J. W. Larrick, R. W. Dodson, and T. H. Howard. 1987. Enhancement of neutrophil superdioxide production by pre-incubation with recombinant tumor necrosis factor. J. Immunol. 139:3783-3791.

36. Ferrante, A., M. Nandoskar, E. J. Bates, D. H. B. Foh, and L. J. Beard. 1988. Tumor necrosis factor beta (lymphotoxin) inhibits locomation and stimulates the respiratory burst and degranulation of neutrophils. Immunology. 63:507-512.

37. Kohno, T., M. T. Brewer, S. L. Baker, P. E. Schwartz, M. W. King, K. K. Hale, C. H. Squires, R. C. Thompson, and J. L. Vannice. 1990. A second tumor necrosis factor receptor gene product can shed a naturally occurring tumor necrosis factor inhibitor. Proc. Natl. Acad. Sci. USA. 87:8331-8335. 